\title{
Enhancing Oxygen Exchange Activity by Tailoring Perovskite Surfaces
}

Yuan Cheng, Abhinav S. Raman, Julian Paige, Liang Zhang, Danyi Sun, Mavis U. Chen, Aleksandra Vojvodic, Raymond J. Gorte, and John M. Vohs*

Department of Chemical and Biomolecular Engineering University of Pennsylvania, Philadelphia, PA USA

\section{Supporting Information}

This file contains the following:

1. The experimental methods used for sample preparation and electrochemical measurements.

2. The computational methods used DFT calculations.

3. The ALD growth rate table and the EIS test results mentioned but not presented in the main text.

4. Surface electronic structure of stoichiometric and defective AO terminated LFO surfaces 


\section{Experimental Methods}

The effect of modifying electrodes via the ALD of oxide thin films was studied using symmetric cells with YSZ electrolyte and either $\mathrm{La}_{1-x} \mathrm{Sr}_{x} \mathrm{FeO}_{3-\delta}(\mathrm{LSF}), \mathrm{La}_{1-\mathrm{x}} \mathrm{Sr}_{\mathrm{x}} \mathrm{MnO}_{3-\delta}(\mathrm{LSM})$ and $\mathrm{La}_{1-\mathrm{x}} \mathrm{Sr}_{\mathrm{x}} \mathrm{CoO}_{3-\delta}$ electrodes. Each cell was constructed using a tri-layer YSZ scaffold consisting of a dense YSZ layer that was $80-\mu \mathrm{m}$ in thickness, sandwiched between two porous YSZ layers that were $35-\mu \mathrm{m}$ in thickness and $60 \%$ porous with an average pore sizes of $\sim 2 \mu \mathrm{m}$. The YSZ tri-layer scaffolds were produced using standard tape casting methods with carbon-based pore formers being used to impart porosity. Detailed descriptions of the synthesis of the YSZ tri-layer can be found in our previous publications ${ }^{1,2}$. LSF, LSM or LSCo were added to the porous electrode layers using multiple cycles of infiltration of an aqueous solution of $\mathrm{La}, \mathrm{Sr}$, and $\mathrm{Fe}, \mathrm{Mn}$ or Co salts $\left(\mathrm{La}\left(\mathrm{NO}_{3}\right)_{3} \cdot 6 \mathrm{H}_{2} \mathrm{O}\right.$ (Alfa Aesar, 99.9\%), $\mathrm{Sr}\left(\mathrm{NO}_{3}\right)_{2}$ (Alfa Aesar, 99\%), and $\mathrm{Fe}\left(\mathrm{NO}_{3}\right)_{3} \cdot 6 \mathrm{H}_{2} \mathrm{O}$ (Fisher Scientific, $98.4 \%), \mathrm{Co}\left(\mathrm{NO}_{3}\right)_{2} \cdot 6 \mathrm{H}_{2} \mathrm{O}$ (J.T.Baker) or $\mathrm{Mn}\left(\mathrm{NO}_{3}\right)_{2} \cdot \mathrm{xH}_{2} \mathrm{O}$ (Alfa Aesar) in a La:Sr:B (B= $\mathrm{Fe}, \mathrm{Mn}, \mathrm{Co}$ ) molar ratio of 0.8:0.2:1, followed by calcining in air at $773 \mathrm{~K}$ for $10 \mathrm{~min}$. Ten infiltration cycles were required to achieve the desired $30 \mathrm{wt} \%$ perovskite loading. After the final infiltration step, the cells were calcined in air at $1123 \mathrm{~K}$ for $1.5 \mathrm{hr}$. A detailed preparation procedure and resulting product morphology can be found in previous publications ${ }^{3,4,5}$. XRD was used to confirm the formation of LSF, LSM or LSCo and to show that no other secondary phases were formed. Some dense LSF slabs were also fabricated for LEIS study. The LSF powders for making dense slabs were prepared via sol-gel methods using the aforementioned solution. After harvesting, these powders were pressed into round wafers and then sintered at $1473 \mathrm{~K}$ for 2 hours to form dense wafers.

ALD of oxide thin films was performed using a homebuilt apparatus that has been described in a previous publication ${ }^{6}$. This system consisted of an adsorption apparatus that could be 
evacuated to approximately 0.02 torr with a mechanical pump. The system had a central chamber to hold the sample which could be heated by an external furnace. The precursors were contained in separate tubes connected to a dosing manifold that could also be heated by an external furnace. The first step in each ALD cycle consisted of evacuating the sample held at the desired temperature, followed by exposure to the precursor vapor. An inert carrier gas was not used in order to minimize any diffusional limitations that may affect adsorption of the precursor into the porous layers of the YSZ scaffold. After the sample was exposed to the precursor, the remaining unreacted precursor molecules were evacuated. After oxidation of adsorbed precursors in a muffle furnace at $773 \mathrm{~K}$ for $10 \mathrm{~min}$, the process was then repeated as needed. The precursors used in this study were $\mathrm{Sr}(\mathrm{TMHD})_{2}, \mathrm{La}(\mathrm{TMHD})_{3}, \operatorname{Pr}(\mathrm{TMHD})_{3}, \mathrm{Ca}(\mathrm{TMHD})_{2}$, and $\mathrm{Mn}(\mathrm{TMHD})_{3}(\mathrm{THMD}=2,2,6,6-$ tetramethyl-3,5-heptanedionato $\left(\mathrm{TMHD}^{-1}\right)$ and were purchased from Strem Chemical, Inc. The deposition temperatures were $578 \mathrm{~K}$ for $\mathrm{Ca}(\mathrm{TMHD})_{2}, 583 \mathrm{~K}$ for $\mathrm{La}(\mathrm{TMHD})_{3}, 523 \mathrm{~K}$ for $\mathrm{Mn}(\mathrm{TMHD})_{3}, 523 \mathrm{~K}$ for $\operatorname{Pr}(\mathrm{TMHD})_{3}$, and $603 \mathrm{~K}$ for $\operatorname{Sr}(\mathrm{TMHD})_{2}$.

To determine the amount of oxide deposited per ALD cycle, gravimetric measurements as a function of the number of ALD cycles were made using a $\gamma-\mathrm{Al}_{2} \mathrm{O}_{3}$ powder (surface area $=120 \mathrm{~m}^{2}$ $\mathrm{g}^{-1}$ ) compressed into wafers. The ALD growth rates are reported as the number of metal cations per $\mathrm{cm}^{2}$ per ALD cycle for each metal oxide in Table S1.

Electrochemical Impedance Spectra (EIS) were measured on symmetric cells in air at $873 \mathrm{~K}$ using a Gamry Instruments potentiostat (1-mA AC perturbation). External electrical connections were made using silver paste and silver wires.

The Low Energy Ion Scattering (LEIS) was performed using a Qtac100 high sensitivity LEIS instrument with $\mathrm{Ne}^{+}$as the probing ion. Initial LEIS experiments showed that the surfaces were contaminated with a carbonate layer most likely formed by reaction with $\mathrm{CO}_{2}$ in the ambient gas 
in the lab. This contaminant layer was removed by lightly sputtering with a $0.5 \mathrm{keV} \mathrm{Ar}^{+}$ion beam (total ion flux to sample $<10^{15} \mathrm{~cm}^{-1}$ ). For the porous infiltrated LSF-YSZ cathodes, due to the complexity of the surface morphology, only two cycles of $10^{14} \mathrm{~cm}^{-2} 90^{\circ}$ incident $0.5 \mathrm{keV} \mathrm{Ne}+$ were performed to remove surface contamination. Comparing to the LEIS result of the fresh samples, the sputtering process boosted the total signal but not change the existence of the major peaks.

\section{Computational methods}

To determine the stable surfaces of LSF under SOFC operating conditions, we calculated the Surface Gibbs Free Energy (SGFE) of the relevant surface terminations using spin-polarized Density Functional Theory (DFT) ${ }^{7,8}$. Due to the large La to Sr ratio in the samples considered in this study, the stable surface terminations of the (001) facet of $\mathrm{LaFeO}_{3}$ were taken as a representative model for LSF. In order to represent the different ALD modified surfaces of LSF investigated in this study, we consider a spectrum of different surface coverages ranging from submonolayer to beyond a monolayer coverage of $\mathrm{AO}$ units by modeling the stoichiometric $\mathrm{BO}_{2}$ and AO terminations, the AO terminations with defects, specifically with $\mathrm{A}, \mathrm{O}$ and an $\mathrm{AO}$ unit vacancy, as well as the O- and A-terminated AO surfaces of LSFO (001) (See Figure 4a for atomic structure). The different surfaces were modelled using either $2 \times 2 \times 7$ or $1 \times 1 \times 7$ symmetric slabs, with the middle 3 layers fixed to their bulk lattice positions, and a vacuum spacing of at least $10 \AA$ was used to prevent interactions between periodic images. All calculations were performed using the Quantum Espresso software package ${ }^{9,10}$ and setup using the Atomic Simulation Environment $(\mathrm{ASE})^{11}$. Kohn-Sham wave functions were expanded using a plane-wave basis set with a kinetic energy cut-off of $500 \mathrm{eV}$. Ultrasoft pseudo-potentials were used to represent the core electrons ${ }^{12}$. 
The Brillouin zone was sampled using a $(5 \times 5 \times 1)$ Monkhorst-Pack k-point grid $^{13}$. Exchange and correlation were described at the Generalized Gradient Approximation (GGA) level using the Perdew-Burke-Ernzerhof (PBE) functional ${ }^{14}$. To account for the errors associated with the on-site Coulomb and exchange interactions, a Hubbard- $\mathrm{U}$ correction $(\mathrm{GGA}+\mathrm{U})$ with $\mathrm{U}=5.3 \mathrm{eV}$ was applied on $\mathrm{Fe}^{15,16}$. All geometries were considered optimized when the maximum force on each atom was less than $0.03 \mathrm{eV} / \AA \AA$.

\section{Tables and Figures}

\section{Table S1. Growth rate for different ALD precursors}

\begin{tabular}{|c|c|c|c|}
\hline Element & Precursor & $\begin{array}{c}\text { Assumed Metal Oxide } \\
\text { Composition }\end{array}$ & $\begin{array}{c}\text { Growth Rate Per } \\
\text { Cycle } \\
\text { (metal atoms cm }\end{array}$ \\
\hline $\mathrm{La}$ & $\mathrm{La}(\mathrm{TMHD})_{3}$ & $\mathrm{La}_{2} \mathrm{O}_{3}$ & $4.8 \cdot 10^{13}$ \\
\hline $\mathrm{Pr}$ & $\mathrm{Pr}(\mathrm{TMHD})_{3}$ & $\mathrm{Pr}_{2} \mathrm{O}_{3}$ & $5.4 \cdot 10^{13}$ \\
\hline $\mathrm{Sr}$ & $\mathrm{Sr}(\mathrm{TMHD})_{2}$ & $\mathrm{SrO}$ & $5.3 \cdot 10^{13}$ \\
\hline $\mathrm{Ca}$ & $\mathrm{Ca}(\mathrm{TMHD})_{2}$ & $\mathrm{CaO}$ & $6.9 \cdot 10^{13}$ \\
\hline $\mathrm{Mn}$ & $\mathrm{Mn}(\mathrm{TMHD})_{3}$ & $\mathrm{Mn}_{2} \mathrm{O}_{3}$ & $5.1 \cdot 10^{13}$ \\
\hline $\mathrm{Zr}{ }^{*}$ & $\mathrm{Zr}(\mathrm{TMHD})_{4}$ & $\mathrm{ZrO}_{2}$ & $5.1 \cdot 10^{13}$ \\
\hline $\mathrm{Fe}^{*}$ & Ferrocene & $\mathrm{Fe}_{2} \mathrm{O}_{3}$ & $8.4 \cdot 10^{13}$ \\
\hline
\end{tabular}

*Data from a previous study performed in our lab(5) 

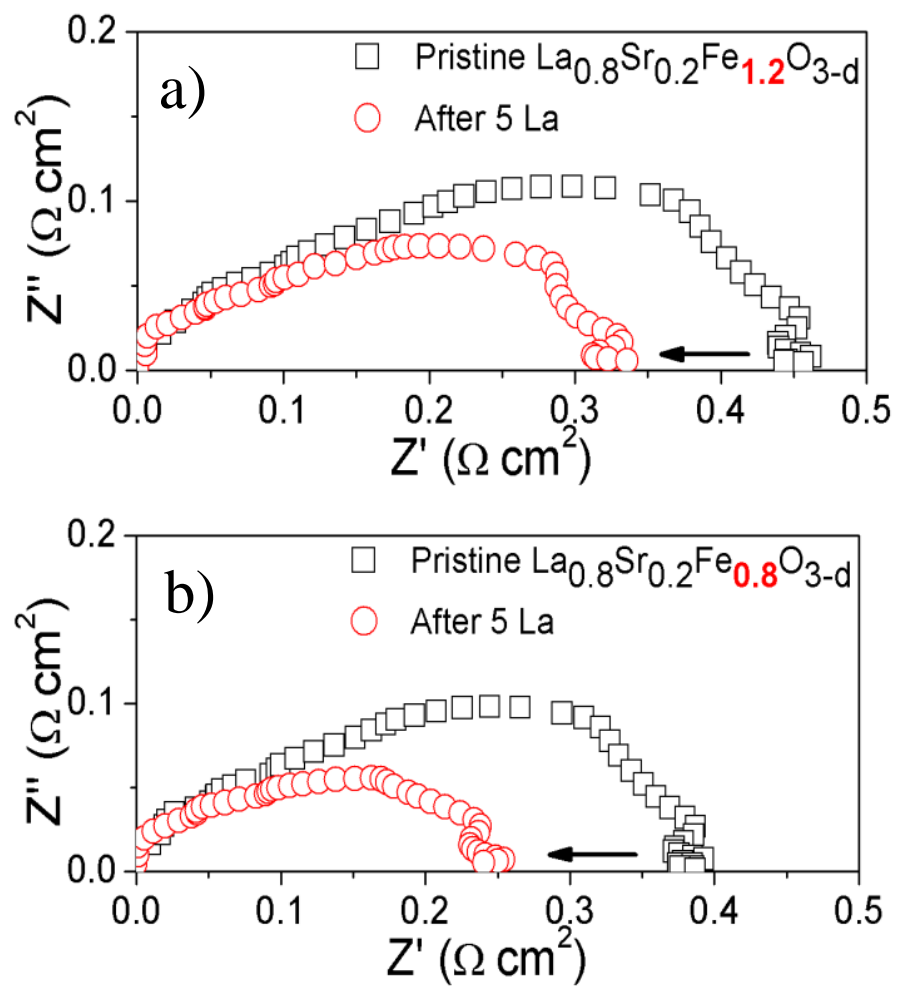

Figure S1. Effect of $\mathrm{La}_{2} \mathrm{O}_{3}$ ALD on infiltrated A-site deficient LSF (a), and B-site deficient LSF (b). Pristine cell performance is denoted as black squares $(\square)$. Red cycles $(\bigcirc)$ show the cell performance after 5 ALD cycles of $\mathrm{La}_{2} \mathrm{O}_{3}$. 

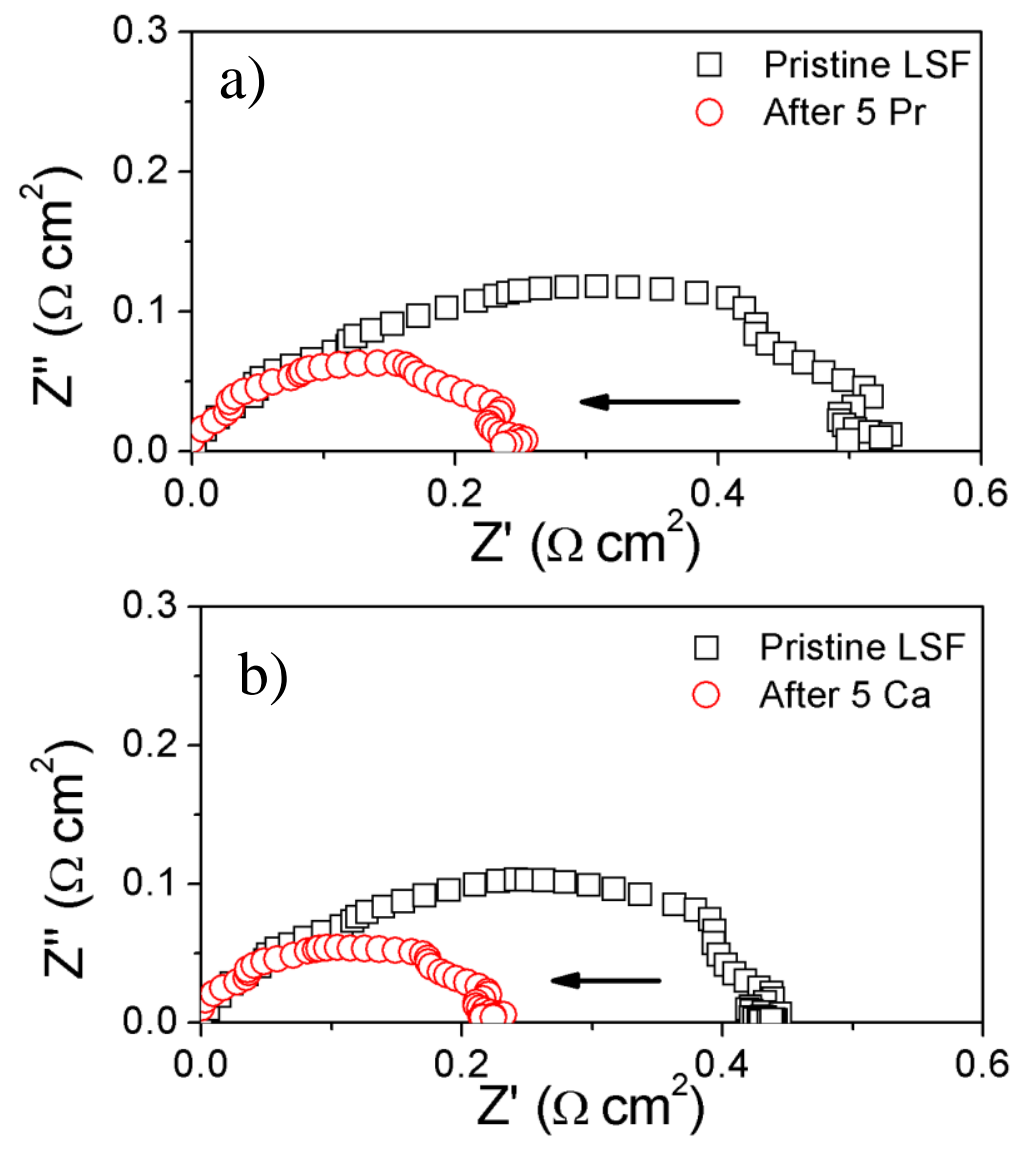

Figure S2. Effect of 5 ALD cycles of $\mathrm{Pr}_{2} \mathrm{O}_{3}(\mathrm{a})$ and $\mathrm{CaO}$ (b) on LSF cells. Pristine cell performance is denoted as black squares $(\square)$. Red cycles $(O)$ show the cell performance after 5 ALD cycles of each metal oxides. 


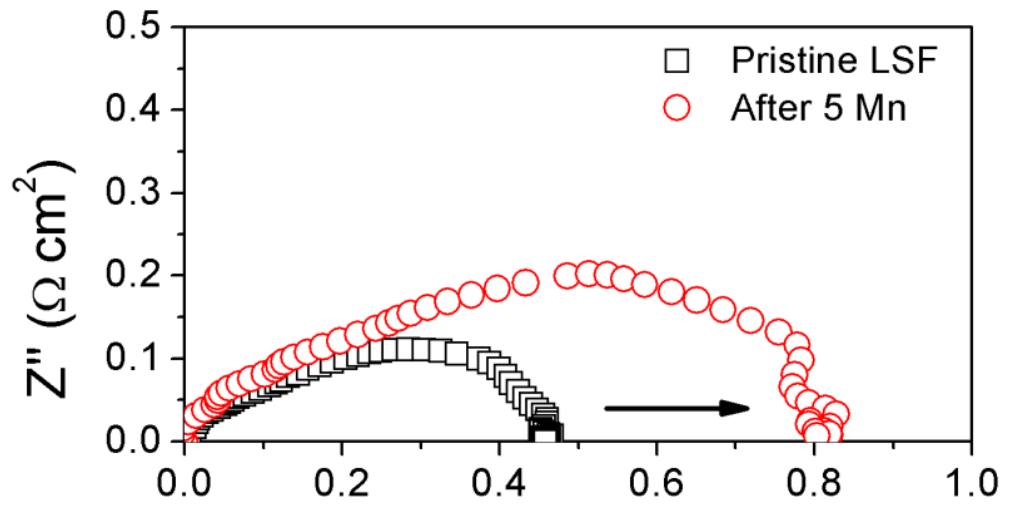

Figure S3. Effect of 5 ALD cycles of $\mathrm{MnO}_{\mathrm{x}}$ on LSF cells. Pristine cell performance is denoted as black squares $(\square)$. Red cycles $(O)$ show the cell performance after 5 ALD cycles. 

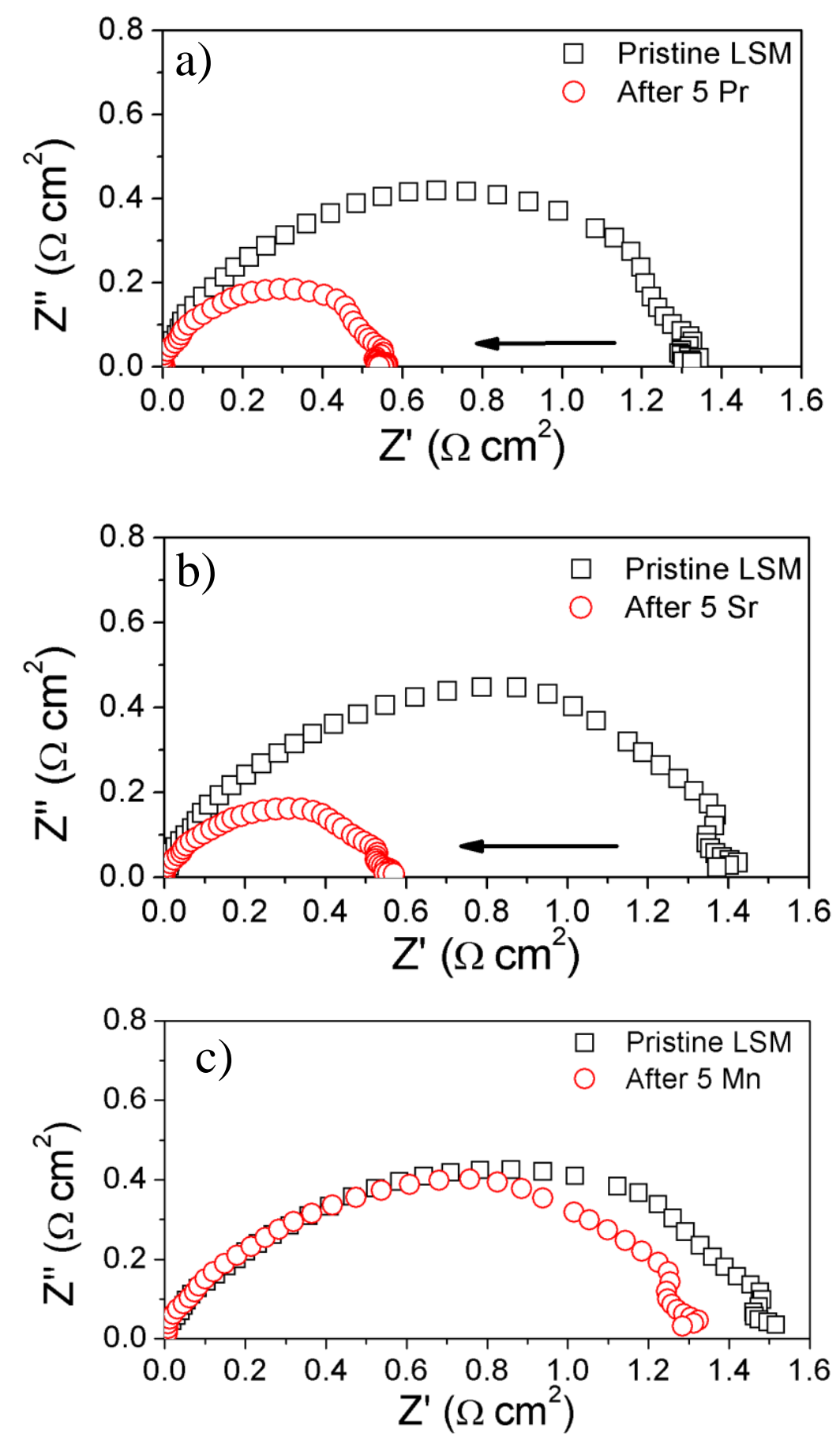

Figure S4. Effect of 5 ALD cycles of $\operatorname{Pr}_{2} \mathrm{O}_{3}(\mathrm{a}), \mathrm{SrO}$ (b), and $\mathrm{MnO}_{\mathrm{x}}$ (c) on LSM cells. Pristine cell performance is denoted as black squares $(\square)$. Red cycles $(O)$ show the cell performance after 5 ALD cycles of each metal oxides. 

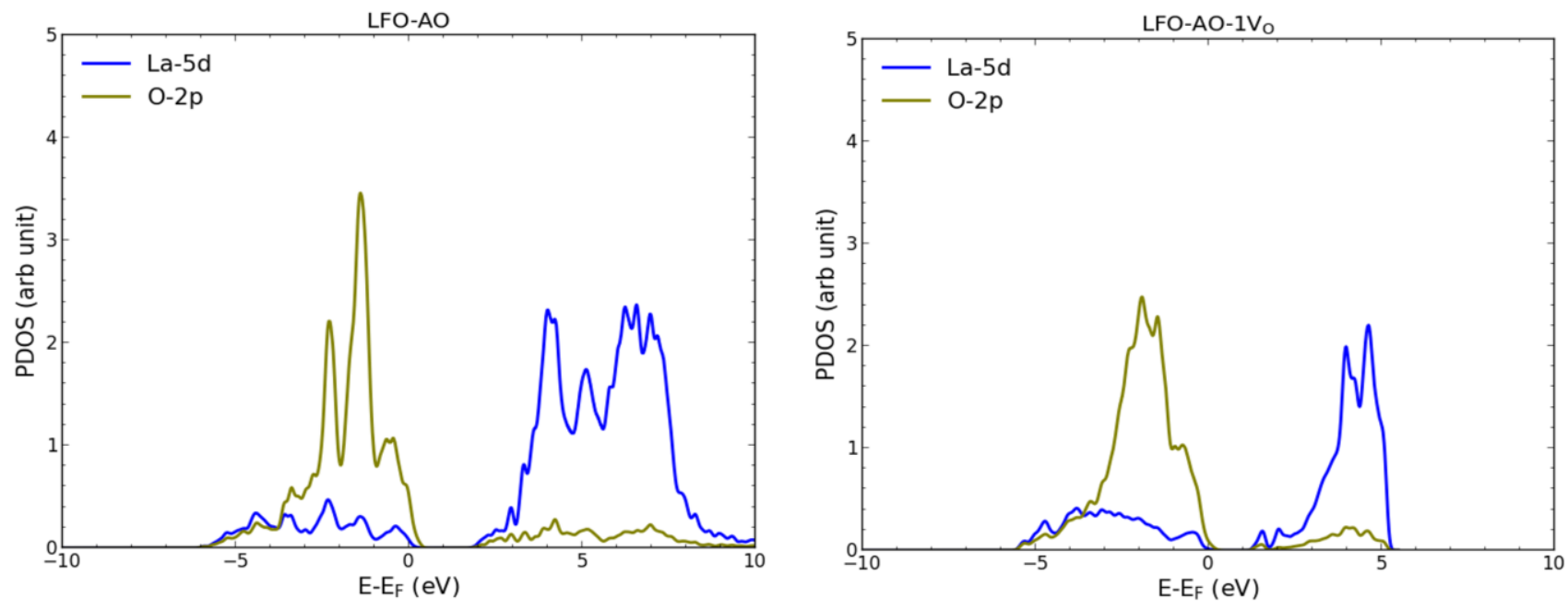

Figure S5. Calculated averaged PDOS (non-spin polarized, $\mathrm{U}_{\mathrm{Fe}}=5.3 \mathrm{eV}$ ) of the surface layer of stoichiometric AO-terminated $\mathrm{LaFeO}_{3}(100)$ surface and AO-terminated surface with an $\mathrm{O}$ vacancy $\left(1 V_{O}\right)$, with respect to the Fermi level $\left(E_{F}\right)$. The calculated surface $\mathrm{O}-2 \mathrm{p}$ band center was found to be: $-0.591 \mathrm{eV}$ and $-1.702 \mathrm{eV}$ for the stoichiometric $\mathrm{AO}$ and $\mathrm{AO}-1 \mathrm{~V}_{\mathrm{O}}$ terminated surfaces, respectively.

\section{References}

(1) Adijanto, L.; Küngas, R.; Park, J.; Vohs, J. M.; Gorte, R. J. SOFC Anodes Based on Infiltration of Tungsten Bronzes. Int. J. Hydrogen Energy 2011, 36 (24), 15722-15730.

(2) Cheng, Y.; Oh, T.-S.; Wilson, R.; Gorte, R. J.; Vohs, J. M. An Investigation of LSF-YSZ Conductive Scaffolds for Infiltrated SOFC Cathodes. J. Electrochem. Soc. 2017, 164 (6), F525F529.

(3) Vohs, J. M.; Gorte, R. J. High-Performance SOFC Cathodes Prepared by Infiltration. Adv. Mater. 2009, 21 (9), 943-956. 
(4) Huang, Y.; Vohs, J. M.; Gorte, R. J. SOFC Cathodes Prepared by Infiltration with Various LSM Precursors. Electrochem. Solid-State Lett. 2006, 9 (5), A237.

(5) Wang, W.; Gross, M. D.; Vohs, J. M.; Gorte, R. J. The Stability of LSF-YSZ Electrodes Prepared by Infiltration. J. Electrochem. Soc. 2007, 154 (5), B439.

(6) Onn, T.; Küngas, R.; Fornasiero, P.; Huang, K.; Gorte, R. Atomic Layer Deposition on Porous Materials: Problems with Conventional Approaches to Catalyst and Fuel Cell Electrode Preparation. Inorganics 2018, 6 (1), 34.

(7) Reuter, K.; Scheffler, M. Composition, Structure, and Stability of (Formula Presented) as a Function of Oxygen Pressure. Phys. Rev. B - Condens. Matter Mater. Phys. 2002, 65 (3), 1-11.

(8) Reuter, K.; Scheffler, M. First-Principles Atomistic Thermodynamics for Oxidation Catalysis: Surface Phase Diagrams and Catalytically Interesting Regions. Phys. Rev. Lett. 2003, 90 (4), 4.

(9) Giannozzi, P.; Baroni, S.; Bonini, N.; Calandra, M.; Car, R.; Cavazzoni, C.; Ceresoli, D.; Chiarotti, G. L.; Cococcioni, M.; Dabo, I.; et al. QUANTUM ESPRESSO: A Modular and Open-Source Software Project for Quantum Simulations of Materials. J. Phys. Condens. Matter 2009, 21 (39), 395502.

(10) Giannozzi, P. et al. Advanced Capabilities for Materials Modelling with Q Uantum ESPRESSO. $J$. Phys. Condens. Matter 2017, 29 (46), 465901.

(11) Larsen, A.; Jens, M.; Jakob, B.; Ivano, C.; Rune, C.; Marcin, D.; Jesper, F.; Michael, G.; Bjork, H.; Cory, H. The Atomic Simulation Environment - A Python Library for Working with Atoms. $J$. Phys. Condens. Matter 2017, 29, 27.

(12) Vanderbilt, D. Soft Self-Consistent Pseudopotentials in a Generalized Eigenvalue Formalism. Phys. Rev. B 1990, 41 (11), 7892-7895.

(13) Monkhorst, H. J. \& Pack, J. D. Special Points for Brillouin-Zone Integrations. Phys. Rev. B 1976, 
$13(12), 588-5192$.

(14) Perdew, J. P., Burke, K. \& Ernzerhof, M. Generalized Gradient Approximation Made Simple. Phys. Rev. Lett. 1996, 77 (18), 3865-3868.

(15) Anisimov, V. I.; Zaanen, J.; Andersen, O. K. Band Theory and Mott Insulators: Hubbard U Instead of Stoner I. Phys. Rev. B 1991, 44 (3), 943-954.

(16) Anisimov, V. I.; Aryasetiawan, F.; Lichtenstein, A. I. First-Principles Calculations of the Electronic Structure and Spectra of Strongly Correlated Systems: LDA + U Method. J. Phys. Condens. Matter 1997, 9, 767-808. 